\title{
Experimental mineralogy of diamond genesis: carbonate-silicate model of growth medium
}

\author{
Litvin Yu.A. \\ Institute of Experimental Mineralogy, Russian Ac. Sci., Chernogolovka, Moscow District, 142432 Russia, \\ litvin@iem.ac.ru
}

Determination of chemical and phase composition of growth medium for diamond and its syngenetic inclusions is of decisive importance for the problem of diamond genesis under the mantle PT conditions (Litvin, 2007). By mineralogical data, diamond was formed as a thermodynamically stable phase in multi-component heterogeneous parent medium. High-pressure high-temperature experiment is particularly advantageous in research of physicochemical conditions of diamond origin. To reveal a growth medium composition has become possible if physicochemical experimental and analytical mineralogical data are in agreement.

Long-term mineralogical study indicates that a variety of minerals, melts and fluids were captured in situ by growing diamond as primary inclusions. Resent research of the inclusions interpreted as trapped fragments of diamond parent medium gives more detailed insight to multi-component material involved into diamond origin (Zedgenizov et al., 2004; KleinBenDavid et al., 2006; Logvinova et al., 2008). Systematization of the mineralogical data points up the significance of multi-component multi-phase system $\mathrm{MgO}-\mathrm{CaO}-\mathrm{FeO}\left(\mathrm{Fe}, \mathrm{Fe}_{2} \mathrm{O}_{3}\right)-\mathrm{MnO}-\mathrm{Na}_{2} \mathrm{O}-\mathrm{K}_{2} \mathrm{O}-$ $\mathrm{Al}_{2} \mathrm{O}_{3}-\mathrm{Cr}_{2} \mathrm{O}_{3}-\mathrm{TiO}_{2}-\mathrm{ZrO}_{2}-\mathrm{SiO}_{2}-\mathrm{P}_{2} \mathrm{O}_{5}-\mathrm{CuS}-$ $\left(\mathrm{Cu}_{2} \mathrm{~S}\right)-\mathrm{FeS}\left(\mathrm{FeS}_{2}\right)-\mathrm{NiS}-\mathrm{KCl}-\mathrm{NaCl}-\mathrm{SiC}-\mathrm{CO}_{2}$ $\left(\mathrm{CO}, \mathrm{CH}_{4}\right)-\mathrm{H}_{2} \mathrm{O}-\mathrm{C}$ for parent medium. It has variable chemical and phase composition and oxidation state. $\mathrm{Mg}, \mathrm{Fe}, \mathrm{Ca}$ silicates, $\mathrm{Na}, \mathrm{K}, \mathrm{Mg}, \mathrm{Ca}, \mathrm{Fe}$ aluminosilicates, $\mathrm{Fe}, \mathrm{Ni}, \mathrm{Cu}, \mathrm{K}$ sulfides, $\mathrm{Mg}, \mathrm{Ca}, \mathrm{Ba}, \mathrm{Fe}$, $\mathrm{K}$, Na carbonates and carbonatites are among the major components. The minor components are presented by Ca phosphate, K, Na chlorides, Si carbide, native Fe, Fe-based alloys, other native metals, fluid C-O-H-N compounds including water $\mathrm{H}_{2} \mathrm{O}$, carbon dioxide $\mathrm{CO}_{2}$, rarely - carbon oxide $\mathrm{CO}$ and methane $\mathrm{CH}_{4}$, nitrogen impurity in diamond, etc. $\mathrm{Mg}, \mathrm{Ca}, \mathrm{Fe}, \mathrm{Ti}, \mathrm{Zr}, \mathrm{Al}, \mathrm{Si}$ oxides belong to both of the component suites. Thus, analytical mineralogy is capable to give a general solution for chemical composition of parent medium for diamond and primary inclusions. At the same time, there is no mineralogical criterion of diamond-forming efficiency for any of chemically variable heterogeneous phases associated with diamond. All this taken to mean that chemical mode and mechanism of diamond formation can not be revealed, and a determination of growth medium for natural diamond (to say, a genetic solution of diamond origin) is unattainable.

Historically, experimental criterion of diamond nucleation was initially used to test the diamondforming efficiency for any of natural materials involved in diamond genesis. Diamond synthesis in melts of mineralogical materials with dissolved carbon is a direct evidence of the efficiency. Diamond nucleation was revealed for multi-component $\mathrm{Na}, \mathrm{K}, \mathrm{Li}, \mathrm{Ca}, \mathrm{Mg}, \mathrm{Fe}, \mathrm{Ba}$, $\mathrm{Sr}$ carbonate, carbonate-silicate and carbonatealuminosilicate melts including natural kimberlitic and carbonatitic ones. The melts of simple and multi- 
component $\mathrm{FeS},(\mathrm{Ni}, \mathrm{Fe})_{9} \mathrm{~S}_{8}, \mathrm{Cu}-\mathrm{Fe}-\mathrm{Ni}-\mathrm{S}$ sulfides, $\mathrm{K}$ and $\mathrm{Na}$ chlorides, strongly compressed water, carbon dioxide and their mixtures with carbonates and silicates were effective as well. Currently, diamond nucleation was run in multi-component $\mathrm{Na}, \mathrm{K}, \mathrm{Mg}, \mathrm{Ca}, \mathrm{Fe}$ silicate melts of compositions based on $\mathrm{Na}_{2} \mathrm{SiO}_{3}$ melt. But, the criterion of diamond nucleation demonstrates that not a solitary one but a wide diversity of relevant materials associated with natural diamond are effective as diamond growth media. To choose the only chemically specific growth medium for dominant mass of natural diamond between the effective materials is impossible. Hence, solution of the problem of the key growth medium for natural diamond is unattainable (even if the nucleation criterion evidence is combined with mineralogical database).

A new experimental criterion of syngenesis of diamonds and their primary inclusions is formulated. It requires that growth medium is to be capable to form both diamond and all the variability of primary inclusions therein. Syngenesis efficiency may be tested with the use of trial-and-error method. In this case, the capability to form both diamonds and primary inclusions is demonstrated for multi-component carbonate-silicate melts derived from peridotite- and eclogite-bearing materials. The role of sulfide melts is not so evident. Therefore, we have only a partial solution. Used as high-pressure melting phase relation study, the criterion disclosed that homogeneous carbonate-silicate and sulfide melts, both diamondforming, are completely immiscible. But, sulfide melts are not capable to dissolve and, as a result, to form silicate and carbonate minerals together with diamond. Therefore, sulfide melts do not agree with syngenesis criterion in contradiction to carbon-oversaturated carbonate-silicate melts which are justified as the mantle growth medium for dominating mass of mantle-derived diamond. Carbonate-silicate melts present the major medium whereas sulfide ones are of subordinated significance.

Physicochemical experimental and analytical mineralogical data if agreed correlate well with the model of carbonate-silicate (carbonatitic) growth medium for the dominant mass of mantle-derived diamond. Recent experimental research made feasible to find the restriction for diamond formation imposed by a concentration barrier of diamond nucleation in compositionally variable carbonate-silicate growth melts. The concentration barrier criterion demonstrates that diamond nucleation in melts of peridotitecarbonatite and eclogite-carbonatite compositions is terminated at carbonatite-rich parts of the systems (no more than $35-45$ wt. $\%$ of silicate constituents). Further development of the diamond genesis problem depends upon investigation of syngenesis phase diagrams in terms of pressure, temperature and composition. First syngenesis diagrams are studied for the multi-component carbonate-silicate systems including carbonatite-peridotite-diamond, carbonatiteeclogite-diamond and melanocratic carbonatite-diamond ones.

It is becomes evident that the dominant multicomponent growth melt oversaturated with dissolved carbon (of outer sources) is based on major completely miscible carbonate and silicate components of the variable concentration ratio. Other chemically diverse components and phases are presented as minor constituents of the major medium. One part of the minor components is completely soluble in the carbonate silicate-melts (oxides, phosphates, chlorides, carbon dioxide, water, components of $\mathrm{C}-\mathrm{O}-\mathrm{H}-\mathrm{N}$ fluid). Another part consists of phases which are completely immiscible with carbonate silicate-melts and insoluble in them (sulfides, native metals). Specific diamond varieties could form in the immiscible melts of insoluble components in limited quantity. Physicochemical mechanism of diamond formation is characterized by diamond nucleation and growth in the growth meltcarbon solution oversaturated in respect to diamond (similarly for major carbonate-silicate and minor sulfide and metal melts in this respect). All this has made possible to determine physicochemical ways of origin of syngenetic inclusions in mantle-derived diamond: (1) from components of the major carbonate-silicate growth 
melt (silicates, aluminosilicates, part of oxides, carbonates, multi-component carbonatitic melts); (2) from minor completely soluble mineral components - in syngenetic relation to diamond (part of oxides, phosphates, chlorides, some others); (3) from minor completely soluble C-O-H-N fluid components - under cooling and solidification of the major carbonate-silicate melts with minor components (water, carbon oxides, methane, some others, which were trapped not as free fluid phases); (4) from minor completely immiscible and insoluble phases (sulfides, metals, some others). By the experimental criterion of syngenesis of diamond and primary inclusions therein and the model of the growth medium composition, the role of admixed C-O-H fluid is of secondary importance: the minor fluid components are not critically important in diamond formation but could have some influence upon kinetics of diamond crystallization in the major carbonate-silicate melts. Support: INTAS grant 05-1000008-7927, RFBR grant 08-05-00110 and RAS program P9.

\section{References.}

Klein-BenDavid J., Wirth R., Navon O., 2006. TEM imaging and analysis of micro inclusions in diamonds: a close look at diamond-growing fluids, American Mineralogist, 91, 353-365.

Litvin Yu.A., 2007. High pressure mineralogy of diamond genesis, in Ohtani, E., ed., Advances in High-Pressure Mineralogy: Geological Society of America Special Paper 421, 83103.

Logvinova A.M., Wirth R., Fedorova E.N., Sobolev N.V., 2008. Nanomentre-sized minerals and fluid inclusions in cloudy Siberian diamonds: new insights on diamond formation, European Journal of Mineralogy, 20, 317-331.

Zedgenizov D.A., Kagi H., Shatsky V.S., Sobolev N.V., 2004. Carbonatitic melts in cuboid diamonds from Udachnaya kimberlite pipe (Yakutia): evidence from vibrational spectroscopy, Mineralogical Magazine, 68, 61-73. 